\title{
Ivermectina: ¿Un antiparasitario frente a SARS-CoV-2?
}

Jorge Arturo Vega-Fernández* 1, a; Danny Omar Suclupe-Campos 1, a; Franklin Rómulo Aguilar-Gamboa 2, a

RESUMEN

La capacidad de propagación y letalidad del SARS-CoV-2 en todo el mundo motiva la urgente necesidad de desarrollar una estrategia terapéutica apropiada para controlar los casos de COVID-19. El desarrollo de nuevos fármacos frente a este nuevo virus es apremiante debido a su rápida diseminación. Se han propuesto alternativas paralelas empleando fármacos ya disponibles para fines similares. Esta revisión describe el potencial antiviral de la ivermectina, así como sus mecanismos de acción frente a algunos virus, y discute su probable aplicación contra el SARS-CoV-2.

Palabras clave: Ivermectina; Infecciones por coronavirus; COVID-19; Proteínas de transporte nucleocitoplasmático; Receptores nicotínicos; Farmacología; Ensayo clínico (Fuente: DeCS BIREME).

\section{Ivermectin: an antiparasitic drug to fight SARS-CoV-2?}

\section{ABSTRACT}

The global spread and lethality of SARS-CoV-2 prompt the urgent need to develop an appropriate therapeutic strategy to control COVID-19 cases. The development of new drugs to fight this novel virus is urgent due to its rapid spread. Parallel alternatives have been proposed by using drugs already available for similar purposes. This review article describes the antiviral potential of ivermectin as well as its mechanisms of action against some viruses, and discusses its probable use to fight SARS-CoV-2.

Keywords: Ivermectin; Coronavirus infections; COVID-19; Nucleocytoplasmic transport proteins; Receptors, nicotinic; Pharmacology; Clinical trial (Source: MeSH NLM).

1 Universidad Nacional Pedro Ruíz Gallo, Facultad de Ciencias Biológicas, Departamento de Microbiología, Grupo de Investigación en Virología e Inmunología del Norte (GIVIN). Lambayeque, Perú.

2 Hospital Regional Lambayeque, Dirección de Investigación, Laboratorio de Inmunología-Virología, Grupo de Investigación en Virología e Inmunología del Norte (GIVIN). Lambayeque, Perú.

a Biólogo, Microbiólogo

*Autor corresponsal. 


\section{INTRODUCCIÓN}

La ivermectina, un derivado semisintético de las avermectinas, es un antiparasitario de amplio espectro utilizado en todo el mundo. Debe su nombre a Streptomyces avermitilis, del cual fue obtenido alrededor de $1970{ }^{(1)}$. Se estima que cada año ha sido utilizada por unos 250 millones de personas para combatir muchas enfermedades parasitarias diferentes, como filariasis, oncocercosis, estrongiloidiasis, sarna y pediculosis; ha demostrado su eficacia contra estas y se ha establecido una dosis óptima para el tratamiento (2). En los adultos se recomienda una única toma de $15 \mathrm{mg}$ $(200 \mu \mathrm{g} / \mathrm{kg})$ por vía oral ${ }^{(3)}$.

En los parásitos, el mecanismo de acción de la ivermectina depende de su efecto sobre los canales iónicos de la membrana celular; puede alterar la motilidad, alimentación y reproducción de los nemátodos. Además, actúa a través de los canales de cloruro dependientes de ligandos, específicamente los activados por el glutamato. De este modo, se une de forma selectiva y con gran afinidad a estos en las células nerviosas y musculares de los invertebrados, y ocasiona un aumento en la permeabilidad de la membrana celular (4). Los canales de cloruro activados por el glutamato (GluCls) están ausentes en los vertebrados y, por lo tanto, su aplicación es segura. Sin embargo, en concentraciones micromolares, la ivermectina puede interactuar con una gama más amplia de canales activados por ligandos que se encuentran tanto en invertebrados como en vertebrados, incluidos los receptores GABA, glicina, histamina y receptores nicotínicos ${ }^{(1,5)}$.

La acción de la ivermectina no se limita a los parásitos. Distintos estudios han demostrado la aplicación de este fármaco como agente quimioterapéutico al actuar en determinadas vías que regulan la proliferación y la metástasis. En estudios in vivo, son eficaces en los cánceres de colon, piel, pulmón, mama, ovario y próstata (1,6-8). Recientemente, ensayos in vitro han comprobado que la ivermectina tiene un efecto antimitótico, al inhibir la despolimerización de los microtúbulos ${ }^{(9)}$. Así mismo, desde 2012 se ha informado del uso de la ivermectina contra Chlamydia trachomatis, Micobacterium tuberculosis y M. ulcerans ${ }^{(10)}$. Los estudios in vitro demostraron que se necesitaban concentraciones significativamente más altas del fármaco para lograr una actividad antibacteriana, muy distinta a la usada como antiparasitario (1). Sin embargo, aún no se ha establecido el mecanismo de acción exacto contra estos patógenos.

Debido a la pandemia del SARS-CoV-2, diferentes grupos de investigación buscan medicamentos eficaces para prevenir o tratar la COVID-19. Las terapias propuestas por ahora están dirigidas principalmente a la estructura y el genoma viral (11). Paralelamente al desarrollo de nuevos medicamentos, la reutilización de los ya existentes parece ser una alternativa frente a la rápida diseminación del virus. En este sentido, la ivermectina ha sido propuesta como tratamiento frente a la COVID-19. Sin embargo, aún no se han definido los mecanismos de acción involucrados sobre su posible actividad antiviral contra el SARS-CoV-2. Por ello, esta revisión sistemática rápida describe la evidencia científica sobre el potencial antiviral de la ivermectina frente a otros virus y, de esta manera, determinar si existe fundamento necesario para utilizarla contra el SARS-CoV-2, al proponer posibles mecanismos por los cuales podría ser efectiva.

\section{Estrategia de búsqueda y criterios de selección}

El criterio de búsqueda de la información estuvo enfocado a determinar los mecanismos de acción antiviral propuestos para la ivermectina. El informe de esta revisión sistemática se realizó de acuerdo con los ítems de referencia para publicar protocolos de revisiones sistemáticas y meta-análisis (PRISMA). El estudio se registró en el repositorio PRISA del INS con el código: 757D250D-B388-4805-8DF3-00CDF052C427; y número de investigación: 1515.

Esta revision incluyó todos los estudios referentes al uso de ivermectina como antiviral, así como los mecanismos de acción que se proponen para este fin. La búsqueda y análisis de la información se realizó en un periodo de dos meses (14 de abril al 20 de junio de 2020). Los tres autores elaboraron las estrategias de búsqueda según las recomendaciones del Manual Cochrane de revisiones sistemáticas ${ }^{(12)}$. Se emplearon términos de búsqueda del vocabulario controlado para MEDLINE (MeSH), enlazados a términos de texto libre para cada uno de los conceptos seleccionados mediante operadores booleanos, para lo cual se emplearon las siguientes palabras: "ivermectin AND coronavirus infection of COVID-19 AND Antiviral therapy OR Antiviral Agents AND SARS-CoV-2"; además, se filtró la información de acuerdo a los últimos diez años. La búsqueda inicial identificó 1875 y 1381 resultados en Pubmed y Scopus, respectivamente. Se eliminaron los artículos duplicados con el programa Mendeley Desktop 1.19.4. Después de filtrar por títulos y resúmenes, evaluamos 124 artículos en texto completo. Se revisaron estos artículos en su totalidad y se seleccionaron 19 que brindaban información específica relacionada con los objetivos de este trabajo. Además, se hizo una búsqueda secundaria a partir de otras fuentes en español como Scielo y Latindex, así como en repositorios de preprints como medRxiv, BioRxiv, OSF Preprints, donde se obtuvo 17 documentos, de los cuales se incluyeron dos estudios adicionales. Finalmente, se incluyeron 21 artículos (Figura 1). 


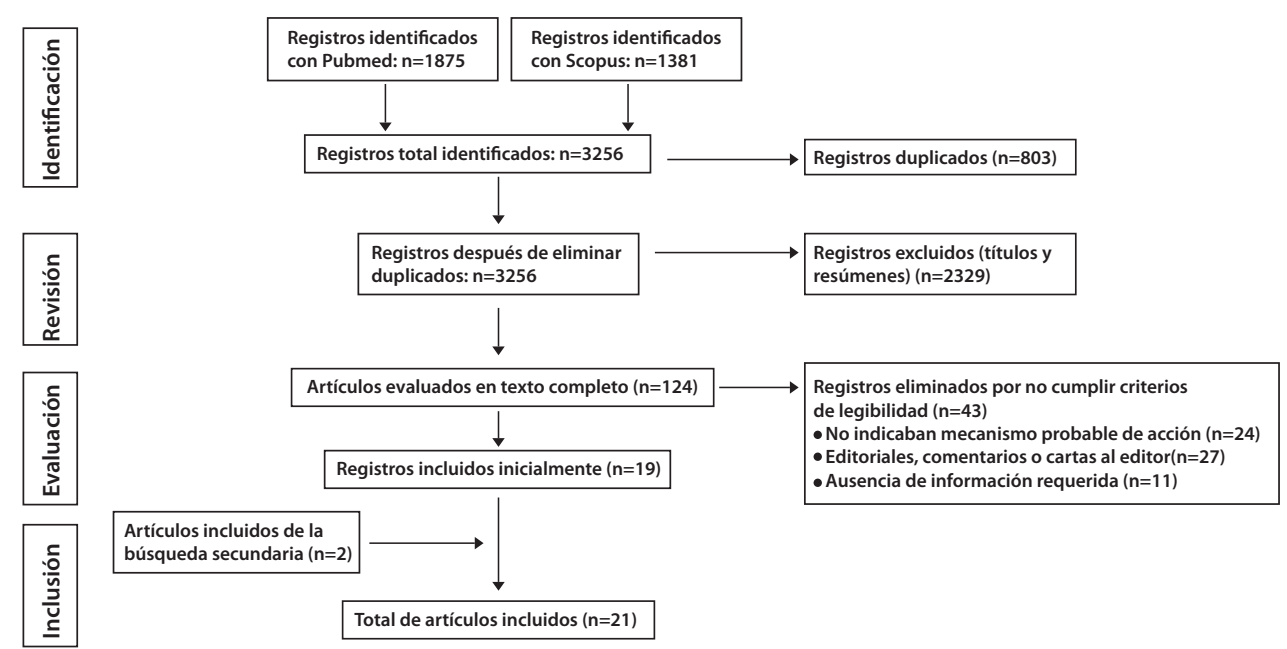

Figuras 1. Flujograma de selección de artículos

\section{Actividad de la ivermectina frente a los virus}

Los estudios in vitro han demostrado el potencial antiviral de la ivermectina contra virus ARN (Tabla 1) porque inhibe su replicación mediante el bloqueo de la actividad de la helicasa viral; esto ocurre, principalmente, en flavivirus como el virus de la fiebre amarilla, el virus del Zika, el virus de la encefalitis equina venezolana, el virus del Nilo Occidental, los 4 serotipos del virus dengue, el virus de la encefalitis japonesa y el virus de la encefalitis transmitida por garrapatas ${ }^{(1,10,13,14)}$ y actúa de manera similar contra el virus de la gripe $\mathrm{A}$, el virus de Newcastle, el virus chikungunya y el virus de inmunodeficiencia humana (VIH-1). En el caso del virus del dengue y el $\mathrm{VIH}-1$, la ivermectina actúa inhibiendo el transporte nuclear de proteínas virales ${ }^{(15,16)}$. También ha demostrado efectividad contra virus ADN (Tabla 1) como el herpesvirus porcino 1 (VPR), causante de la pseudorrabia (17), herpesvirus bovino $1{ }^{(18)}$ y parvovirus del cangrejo de río ${ }^{(19)}$, en los que, probablemente, actúe en las importinas nucleares.

Los estudios in vivo de la ivermectina como terapia antiviral son escasos. Se ha demostrado, tanto in vitro como in vivo, que aumenta la supervivencia en ratones infectados con VPR ${ }^{(17)}$, mientras que en otros estudios in vivo en cangrejos de río infectados con parvovirus, su aplicación limita la reproducción viral ${ }^{(19)}$, de manera similar en embriones de pollo infectados con el virus de Newcastle ${ }^{(20)}$. También se ha informado su acción indirecta en aves como controlador del vector del virus del Nilo Occidental (19). Asimismo, en Tailandia, la ivermectina formó parte de un ensayo clínico de fase III para determinar su eficacia y confirmar la seguridad del tratamiento en pacientes adultos infectados por dengue. Se observó una reducción significativa en los niveles séricos del antígeno viral NS1, pero no eficacia clínica del tratamiento ${ }^{(21-23)}$.

Tabla 1. Estudios sobre el efecto antiviral de la ivermectina

Mecanismo de

acción antiviral
Objetivo diana

Virus
Tipo de estudio
Dengue 1-4 $(16,24,25)$

Influenza A (26)

Virus de la encefalitis equina venezolana

(VEEV) (27)

Virus de la inmunodeficiencia

humana-1(VIH-1) ${ }^{(16)}$

Herpes bovino 1 (18)

Parvovirus del cangrejo de río ${ }^{(19)}$

Zika (ZIKV) (24)

Virus del Nilo Occidental (24)

Herpesvirus equino tipo 1 (EHV-1) ${ }^{(28)}$

Poliomavirus BK (BKPyV) ${ }^{(29)}$

Virus Hendra (HeV) ${ }^{(30)}$

Circovirus porcino 2 (PCV2) ${ }^{(31)}$
In vitro

In vitro

In vivo 


\begin{tabular}{|c|c|c|c|}
\hline $\begin{array}{l}\text { Mecanismo de } \\
\text { acción antiviral }\end{array}$ & Objetivo diana & Virus & Tipo de estudio \\
\hline $\begin{array}{l}\text { Inhibición en la } \\
\text { síntesis de ARN viral }\end{array}$ & $\begin{array}{l}\text { Inhibidor de la } \\
\text { helicasa NS3 } \\
\text { - }\end{array}$ & $\begin{array}{l}\text { Virus de la fiebre amarilla }{ }^{(13)} \\
\text { Virus del dengue }{ }^{(13)} \\
\text { Virus de la encefalitis japonesa }{ }^{(13)} \\
\text { Virus de la encefalitis transmitida por } \\
\text { garrapatas }{ }^{(13)} \\
\text { Virus de Chikungunya (CHIKV) }{ }^{\left({ }^{(32)}\right.}\end{array}$ & In vitro \\
\hline $\begin{array}{l}\text { Inhibición en la } \\
\text { síntesis de ADN viral }\end{array}$ & $\begin{array}{l}\text { Inhibidor de la ADN } \\
\text { polimerasa UL42 }\end{array}$ & Virus de la pseudorrabia (PRV) ${ }^{(17)}$ & $\begin{array}{l}\text { In vitro } \\
\text { In vivo }\end{array}$ \\
\hline Como agente ionóforo & - & Virus con envoltura ${ }^{(33)}$ & In silico \\
\hline Desconocido & - & $\begin{array}{l}\text { Virus del Nilo Occidental }{ }^{(34)} \\
\text { Virus del síndrome respiratorio y } \\
\text { reproductivo porcino (PRRSV) }{ }^{(35)} \\
\text { Virus de la enfermedad de Newcastle }{ }^{(20)}\end{array}$ & $\begin{array}{l}\text { In vitro } \\
\text { In vitro } \\
\text { In vivo }\end{array}$ \\
\hline
\end{tabular}

Se ha propuesto que el mecanismo de acción de la ivermectina contra los virus consiste en inhibir la importación nuclear de factores sustanciales para su replicación. Se ha identificado que inhibe la entrada nuclear de la proteína integrasa (IN) del VIH-1. En el caso del dengue, la ivermectina interrumpe específicamente la interacción entre la proteína viral NS5 y la proteína $\mathrm{Imp} a / B 1$, lo que impide su ingreso al núcleo celular ${ }^{(24)}$, para ello, se propone que actúa sobre la proteína Imp a/B1 impidiendo su formación, y se une al dominio de repetición IMPa armadillo (ARM) (16,24). Otros estudios proponen que la ivermectina inhibe la actividad de la helicasa no estructural (helicasa NS3) en el virus de la fiebre amarilla, principalmente, pero con menor eficacia contra otros flavivirus como la encefalitis japonesa, el dengue y los virus de la encefalitis transmitida por garrapatas ${ }^{(16)}$. Con base en la evidente actividad en los virus, a continuación se detallan los probables mecanismos acción de la ivermectina frente al SARS-CoV-2.

\section{POSIBLES MECANISMOS DE ACCIÓN DE IVERMECTINA FRENTE A SARS-COV-2}

\section{Interrupción en el transporte nuclear de las proteínas virales}

La replicación de los coronavirus se lleva a cabo generalmente en el citoplasma de las células infectadas, pero en varias familias de virus ARN envueltos como Arteriviridae, Flaviviridae, Paramyxoviridae y en la misma Coronaviridae, existen ciertas proteínas estructurales localizadas en el núcleo y/o nucleolo que intervienen en determinados momentos del ciclo de vida viral, sobre todo al comienzo de la infección ${ }^{(36-38)}$. Una de ellas es la proteína de la nucleocápside $(\mathrm{N})$, implicada en importantes funciones de replicación, ensamblaje, gemación y liberación de partículas virales (Figura 2). La única vía de transporte dentro y fuera del núcleo es a través de los complejos de poros nucleares (NPC) mediados por miembros de la superfamilia de importinas, que reconocen secuencias de localización nuclear (SLN) o secuencias de exportación nuclear (SEN) en las moléculas de carga para el transporte dentro y fuera del núcleo. La vía de importación nuclear mejor estudiada está mediada por el heterodímero importin- $\alpha / B 1$, donde importin- $\alpha$ reconoce y se une directamente a los SLN de la carga, e importin-B1 media la unión del complejo de importación. La exportación nuclear es análoga a la importación nuclear ${ }^{(37-39)}$. Se ha revelado que el IMPa/B1 participaría en el cierre nucleocitoplasmático dependiente de la señal de la proteína $\mathrm{N}$ de SARS-CoV ${ }^{(40)}$. Al considerar estos informes en conjunto, se ha sugerido que la ivermectina puede ser eficaz al bloquear el transporte nuclear de la proteína $\mathrm{N}$ del SARS-CoV-2 (Figura 2a).

Para demostrar la actividad antiviral de la ivermectina hacia el SARS-CoV-2, Caly et al. ${ }^{(41)}$ cultivaron líneas celulares Vero/ hSLAM, a las 24 horas las infectaron con aislados clínicos de SARS-CoV-2 durante 2 horas, luego las trataron con ivermectina 5 uM, y las incubaron entre 0 y 3 días. Luego de 48 horas, se observó una reducción de $\sim 5000$ veces del ARN viral, lo que indica, para los autores, que el tratamiento con ivermectina resultó en la pérdida efectiva de todo el material viral, y determina una Cl50 de $2 \mu \mathrm{M}$ para el tratamiento en condiciones antes mencionadas ${ }^{(41)}$. Aunque los resultados del estudio in vitro demuestran que la ivermectina en una sola dosis puede controlar la replicación viral en 24 a 48 horas, estos hallazgos requieren una validación adicional eficiente con modelos in vivo que se contraste con estudios clínicos.

\section{Actividad como agente ionóforo}

Otra probable vía indica que la ivermectina puede desempeñar un papel secundario contra ciertos virus al actuar como agente ionóforo ${ }^{(33)}$. Un ionóforo es una molécula constituida 
por una cavidad interna hidrofílica (sitio de unión específico para cationes, principalmente) y una superficie externa hidrofóbica, que permite al complejo unirse a las membranas celulares y virales de virus con envoltura y así alterar el equilibrio hidroelectrolítico ${ }^{(42)}$. Se postula que al unirse dos moléculas de ivermectina (en un modo de "cabeza-cola") se generaría un complejo ionóforo. Sin embargo, para obtener la configuración mencionada, ambas moléculas deben unirse y posicionarse correctamente, lo que podría ocurrir espontáneamente o estar mediado por proteínas de transporte plasmático, como la albúmina ${ }^{(43)}$. De esta manera, la parte interna del complejo, al ser de naturaleza hidrófoba, permitiría el transporte de iones a través de la membrana viral, lo que ocasionaría un desequilibrio iónico entre el ambiente externo e interno, con la recuperación del agua y la consecuente lisis osmótica (Figura 2b). Esta hipótesis aplicaría para virus sin una cápside proteica como el SARS-CoV-2, que tiene una envoltura a base de fosfolípidos que protege su material genético. Además, la variación en la concentración de cationes podría inhibir algunas enzimas clave en la replicación viral, como las ARN polimerasas dependientes de ARN ${ }^{(44)}$. En combinación, estos mecanismos permitirían neutralizar al virus en la etapa temprana de la infección a células huésped. Esta hipótesis también deberá ser confirmada mediante simulaciones bioinformáticas y análisis fisicoquímicos detallados.

\section{Interacción con la helicasa viral nsp13}

El gen ORF1ab del SARS-CoV-2 es una poliproteína que se divide en 16 proteínas no estructurales (NSP) y ocupa aproximadamente dos tercios del genoma viral (45). En los nucleótidos, el genoma muestra una gran similitud con el genoma del SARS-CoV. Respecto a los aminoácidos, el porcentaje de identidad varía, pero la mayoría de las secuencias comparten una gran similitud. Las secuencias de la proteína helicasa de los dos virus son casi idénticas y comparten una identidad del 99,83\% sobre la longitud completa de la secuencia. En los coronavirus a, B y $\mathrm{\gamma}$, las secuencias de la proteína helicasa ${ }^{(46)}$ se muestran muy conservadas, mientras que la helicasa nsp13 de SARS-CoV-2 es la que es más estructuralmente similar a la del SARS-CoV y MERS-CoV ${ }^{(47)}$. La alta conservación de esta proteína en la familia de los coronavirus la convierte en un blanco ideal para los fármacos antivirales de amplio espectro y también reduce las posibilidades de selección de cepas resistentes a inhibidores.

En un estudio reciente se diseñó un modelo de homología de la helicasa SARS-CoV-2 basado en la estructura cristalina de la helicasa de MERS-CoV denominada 5WWP para determinar si la helicasa de SARS-CoV-2 es un objetivo potencial de la ivermectina mediante un análisis de fármacos in silico. En el proceso de selección se incluyeron 10 medicamentos estructuralmente similares a la ivermectina sobre la base de las afinidades de unión a la helicasa SARS-CoV-2. Los resultados indicaron que nistatina e ivermectina son los socios de unión de energía más bajos de la helicasa SARSCoV-2, a la que se unen con afinidades iguales $(8,8 \mathrm{kcal} /$ $\mathrm{mol}$ ) en sitios diferentes pero adyacentes ${ }^{(48)}$. Ambos compuestos mostraron una interacción extensa con residuos de helicasa, específicamente con las regiones de unión a oligonucleótidos. Por lo tanto, la ivermectina podría ejercer un efecto antiviral al inicio de la replicación del ARN viral, la única fase en que la helicasa está activa ${ }^{(37)}$ (Figura 2c). En el SARS-CoV-2, este mecanismo requiere de más investigaciones, pero los inhibidores de la actividad de helicasa nsp13 ofrecen una posible opción terapéutica para las infecciones por coronavirus.

\section{La hipótesis nicotínica y su efecto como modulador alostérico positivo}

La hipótesis nicotínica propone que SARS-CoV-2 no solo utiliza la enzima convertidora de angiotensina 2 (ECA2) para ingresar a las células susceptibles de los pulmones y del sistema olfativo, sino que también intervienen otros receptores, como el receptor nicotínico de acetilcolina (nAChR) que está ampliamente distribuido en las neuronas, células del sistema inmune (incluidos los macrófagos), células cardiacas, células del epitelio bronquial, células del epitelio alveolar tipo II y los fibroblastos intersticiales pulmonares en los que se expresa específicamente el subtipo a7, lo que contrasta con la idea, sostenida hasta ahora, de que ECA2 es el principal receptor de entrada celular $(49,50)$. La función del nAChR es unir, a través de la ruta aferente o eferente del nervio vago, a la acetilcolina u otros agonistas del sistema colinérgico nicotínico que modifican y controlan la respuesta inflamatoria, e inhiben el TNF segregado por los macrófagos ${ }^{(51,52)}$. Este mecanismo fisiológico se conoce como vía "colinérgica antiinflamatoria", y su disfunción, debida a la interacción viral con el receptor nAChR (Figura 2d), explicaría los síntomas hiperinflamatorios observados en los pacientes con infección severa de COVID-19 y también los múltiples casos de anosmia y ageusia notificados, con la hipótesis de que serían parte de otro signo de disfunción del sistema colinérgico nicotínico ${ }^{(52)}$.

Por consiguiente, se ha planteado que la nicotina y otros agentes moduladores nicotínicos ortostéricos $\mathrm{y} / \mathrm{o}$ alostéricos, como la ivermectina, podrían actuar como agonistas competitivos de $a 7-n A C h R$ al restaurar la función comprometida del sistema colinérgico nicotínico (Figura 2d) y restablecer así la respuesta inmunológica equilibrada en los casos graves ${ }^{(49)}$. A partir de esta hipótesis, la COVID-19 parece convertirse, eventualmente, en una enfermedad del sistema colinérgico nicotínico ${ }^{(52)}$.

\section{Ivermectina como inmunomodulador}

La inmunomodulación se refiere a la manipulación del sistema inmunológico mediante el uso de sustancias de origen farmacológico o biológico para inducir una respuesta inmunológica apropiada al estado que se desea tratar o prevenir. Así pues, en algunos casos y según la enfermedad, 
la finalidad de la modulación será aumentar la intensidad de la respuesta inmune como en las infecciones producidas por agentes patógenos $u$ otras situaciones en las que el sistema inmunológico está disminuido por alguna causa (inmunosupresión, estrés, infecciones crónicas). En otros casos, la inmunomodulación consistirá en regular una respuesta inmunológica fuera de control (enfermedades autoinmunes, alérgicas, trasplantes, hipersensibilidad). De este modo, se ha demostrado que ciertos fármacos antiparasitarios tienen actividad inmunomoduladora, como el tiabendazol, el oxfendazol, el fenbendazol, el metronidazol y la ivermectina ${ }^{(53)}$. Esta última ha demostrado un potencial favorable, mediante pruebas in vivo, para actuar como un modulador positivo de la respuesta inmune: en 1991 se observó que tenía la capacidad de potenciar la respuesta dependiente de las células $T$ en ratones ${ }^{(54)}$. En estudios realizados en conejos, se determinó que la ivermectina tiene una respuesta inmunopotenciadora dependiente de la dosis contra el antígeno tipo II de Pasteurella multocida (un polisacárido capsular), es decir, que a medida que la dosis aumenta, se incrementa la respuesta inmunológica, y viceversa ${ }^{{ }^{53} \text {. El tratamiento con ivermectina también }}$ aumentó significativamente la producción de IL-1 b y TNF-a en células mononucleares de pacientes con oncocercosis ${ }^{(55)}$. Estos hallazgos de inmunoestimulación celular y humoral sugieren que la ivermectina podría mejorar la respuesta inmunológica de manera positiva, es decir, producir efectos inmunopotenciadores que podrían ser útiles en las primeras etapas de la infección. Sin embargo, bajo la evidencia citada anteriormente, su uso en pacientes en etapas intermedias 0 tardías de COVID-19 sería muy contraproducente.

Farmacocinética y farmacodinámica de la ivermectina Para estudiar el comportamiento farmacocinético y farmacodinámico de la ivermectina es necesario considerar varios elementos como la vía de administración, la formulación utilizada y el estado fisiopatológico del paciente ${ }^{(56)}$. La vía oral

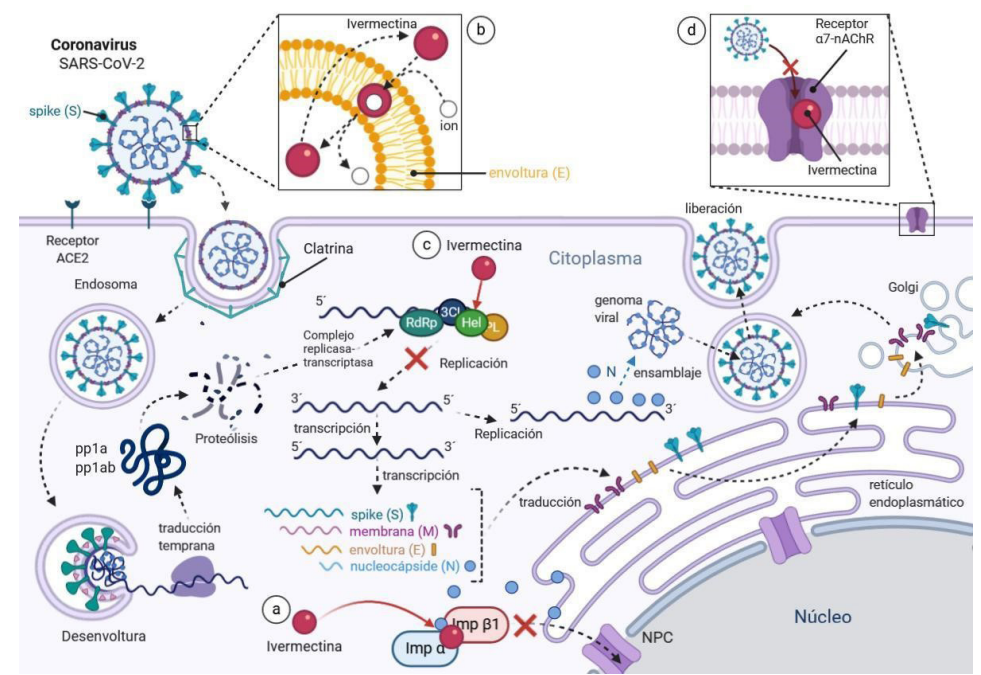

a) Inhibe el transporte nuclear de la proteína $\mathrm{N}$, al unirse a la subunidad a del heterodímero Importin-a/B1 de la célula huésped; b) actúa como agente ionóforo con alteración en el equilibrio osmótico de la membrana viral; c) inhibe la actividad de la helicasa nsp13 e interrumpe la replicación del material genético viral; d) actúa como agonista competitivo del receptor a7-nAChR con modificación de la respuesta inmune

Figuras 2. Posibles mecanismos de la actividad antiviral de la ivermectina contra el SARS-CoV-2 


\section{DISCUSIÓN}

El uso de ivermectina ha sido promovido durante la actual pandemia, principalmente en América Latina ${ }^{(62)}$, donde en países como el Perú se propone su empleo masivo de forma ambulatoria en pacientes con riesgo de infección, desde los centros de salud y en fases tempranas de la enfermedad, porque se cree que "puede dar buenos resultados". Aunque se reconoce que no existe en el mundo un tratamiento aprobado y eficaz para la enfermedad, asesores y expertos en la materia afirman "que se debe hacer el máximo esfuerzo para reducir la progresión de la pandemia" (63). En este sentido, el uso de este fármaco ha sido promovido por las declaraciones respecto a su éxito, las cuales provienen tanto de médicos especialistas ${ }^{(64)}$ como de personas que han sufrido de COVID-19 ${ }^{(65)}$.

La ivermectina tiene un importante potencial antiviral demostrado contra los virus ADN y ARN que afectan animales y humanos, y sugiere una teórica inhibición del SARS-CoV-2 en la etapa temprana de la infección. El estudio de Caly et al. ${ }^{(41)}$ es la principal evidencia de la que se dispone hasta el momento. Sin embargo, es necesario mencionar aspectos de la farmacocinética de este medicamento para considerar el verdadero impacto de este estudio. Si bien los efectos antivirales de la ivermectina contra el SARS-CoV-2 son prometedores, su reutilización y dosis están en conflicto. La dosis de ivermectina utilizada habitualmente es de $200 \mathrm{ug} / \mathrm{kg}$ y que alcanza una concentración plasmática de $40 \mathrm{ng} / \mathrm{ml}$, mientras que Solomon et al. (66) utilizan una dosis es de $2,5 \mathrm{uM}$, que equivale a $2200 \mathrm{ng} / \mathrm{ml}$, es decir, se sugiere emplear una concentración 50 veces mayor a la dosis normal para alcanzar los niveles plasmáticos necesarios para ejercer un posible efecto sobre SARS-CoV-2. En cuanto a esta información, la FDA ${ }^{(60)}$ destacó que este tipo de estudio in vitro se realiza, generalmente, en las primeras etapas del desarrollo de fármacos, y que es necesario realizar más ensayos para confirmar la seguridad y la eficacia de la ivermectina para uso humano para tratar la COVID-19, ya que la actividad de la ivermectina, hasta el día de hoy, no se ha reproducido en modelos animales ni se ha demostrado clínicamente.

En la presente revisión se proponen cuatro mecanismos probables de acción de la ivermectina contra el SARS-CoV-2. En cuanto a la interrupción del transporte nuclear, este depende principalmente de las exportinas e importinas y de una secuencia de aminoácidos en específico, denominada señales de localización nuclear (NLS), que reconocen las proteínas que se van a transportar. La evidencia del uso de estas moléculas por la familia Coronaviridae es inexistente, ya que algunos estudios indican que la proteína $\mathrm{N}$ del SARS-CoV no parece ingresar al núcleo, lo que sugiere que las NLS están inactivas o son inaccesibles y que hay dominios adicionales que son responsables de retener la proteína $\mathrm{N}$ en el citoplasma ${ }^{(40)}$. A pesar de ello, es importante considerar que estos mecanismos no se han investigado específicamente en el SARS-CoV-2, y dada la evidencia de ello en otros virus de tipo ARN como el dengue y el VIH (Tabla 1), sería importante continuar la investigación.

La ivermectina actúa como un ionóforo y regula los canales de cloruro para generar apoptosis y muerte celular osmótica, un mecanismo ya descrito frente a células tumorales (67). En este estudio planteamos una vía similar contra el SARSCoV-2, ya que es un virus que tiene envoltura. Otros agentes ionóforos han demostrado actividad antiviral porque alteran directamente la cinética del flujo de protones en las partículas e impiden la acidificación endosomal, como en el caso del fármaco salinomicina contra la proteína $M 2$ del virus de la gripe ${ }^{(68)}$. Para el SARS-CoV-2 proponemos una vía extracelular con una acción directa sobre la envoltura, con base en lo descrito por algunos investigadores $(33,42,43)$.

Las helicasas son objetivos prometedores para los fármacos antivirales porque sus actividades enzimáticas son esenciales para la replicación, transcripción y traducción del genoma viral. Se ha informado de la existencia de numerosos y potentes inhibidores de helicasas codificadas por el virus del herpes simple, el virus de la hepatitis $C$, el virus de la encefalitis japonesa, el virus del Nilo Occidental, el virus del papiloma humano $y$, de manera muy interesante, por el SARS-CoV. Todas las helicasas comparten una función motora común impulsada por la hidrólisis del ATP, pero difieren exactamente en la forma en que el motor mueve la proteína y su carga en una cadena de ácido nucleico ${ }^{(69)}$. Debido a la evidencia, esta sería una de las vías más probables que emplearía la ivermectina.

La hipótesis nicotínica propone que el SARS-CoV-2 no solo utiliza la enzima convertidora de angiotensina 2 (ACE2) para su ingreso a las células, sino otro receptor denominado a7-nAChR. La descripción y propuesta de otros receptores frente a la infección por SARS-COV-2 no es nueva. De hecho, la molécula CD147 presente en muchos tipos celulares también ha sido propuesta como una importante vía de entrada para el SARS-CoV-2 (70). Por ello, las manifestaciones multisistémicas de SARS-CoV-2 podrían atribuirse a la presencia de más de un receptor, lo que explicaría las diferentes manifestaciones clínicas que ocasiona, además de las respiratorias.

De las publicaciones revisadas, solo se ha completado un estudio observacional (71) que pretende evaluar la eficacia de la ivermectina e hidroxicloroquina como terapia combinada con los antibióticos doxiciclina y azitromicina, y comparar el período de recuperación de estos dos fármacos aplicados como monoterapia central; sin embargo, todavía no ha publicado oficialmente sus resultados. Cabe destacar la importancia de aplicar estudios clínicos apropiados para demostrar la eficacia y la seguridad de la droga para el 
tratamiento de COVID-19. Un ejemplo claro es el brote de Ébola de 2014, en el que unas 30000 personas desarrollaron la enfermedad y se probaron numerosas terapias contra este virus, como la cloroquina, la hidroxicloroquina, el favipiravir, el brincidofovir, los anticuerpos monoclonales, el ARN antisentido y el plasma convaleciente, entre muchas otras ${ }^{(72)}$, aunque no se ha llegado a una conclusión sobre su eficacia. Algunos de los estudios que se llevan a cabo son observacionales, mientras que la mayoría de ensayos clínicos son de intervención; sin embargo, cabe señalar que los ensayos con controles aleatorizados y doble ciego con criterios de exclusión claramente definidos y que evalúan una población lo más heterogénea posible son los que tienen menos riesgo de sesgo y proporcionan resultados válidos para la adopción de decisiones sobre el uso de la ivermectina.

Los hallazgos expuestos indican que la ivermectina tiene un potencial significativo frente a SARS-CoV-2. Sin embargo, la única evidencia disponible que demuestra la eficacia antiviral de este fármaco se ha descrito a nivel in vitro, y todavía no hay estudios clínicos concluidos que respalden su utilidad en el tratamiento de pacientes afectados por COVID-19. Hasta el 20 de junio de 2020 se dispone de 27 estudios que evalúan el uso de ivermectina para COVID-19 (https://clinicaltrials.gov/) (71), los cuales, sin duda, influirán en el manejo de esta nueva enfermedad.

\section{CONCLUSIÓN}

El desarrollo de nuevos fármacos frente a SARS-CoV-2 es apremiante durante el desarrollo de la actual pandemia. Se han propuesto alternativas paralelas que emplean medicamentos ya disponibles para fines similares. La presente revisión sistemática demuestra que existe el fundamento necesario para motivar la investigación y proponer ensayos clínicos que permitan usar la ivermectina frente a SARS-CoV-2. Así mismo, se han detallado los mecanismos de acción más probables del fármaco frente al virus.

Contribuciones de autoría: Todos los autores participaron por igual en la interpretación de la evidencia encontrada, la revisión crítica y la aprobaron la versión final del manuscrito.

Fuente de financiamiento: El artículo fue financiado por los autores.

\section{Conflicto de interés: Los autores declaran no tener ningún} conflicto de interés.

\section{REFERENCIAS BIBLIOGRÁFICAS}

1. Laing R, Gillan V, Devaney E. Ivermectin - old drug, new tricks? Trends Parasitol. 2017; 33(6): 463-72.
2. Ashour DS. Ivermectin: from theory to clinical application. Int J Antimicrob Agents. 2019; 54(2): 134-42.

3. Bethesda (MD): National Institute of Diabetes and Digestive and Kidney Diseases. Ivermectin. En: National Institutes of Health, editor. LiverTox: clinical and research information on drug-induced liver injury [Internet]. 2018. Disponible en: https://www.ncbi.nlm. nih.gov/books/NBK548921/

4. Yates DM, Portillo V, Wolstenholme AJ. The avermectin receptors of Haemonchus contortus and Caenorhabditis elegans. Int J Parasitol. 2003; 33(11): 1183-93.

5. Wolstenholme AJ, Rogers AT. Glutamate-gated chloride channels and the mode of action of the avermectin/milbemycin anthelmintics. Parasitology. 2006; 131(Suppl. 1): 585.

6. Yin J, Park G, Lee JE, Choi EY, Park JY, Kim T-H, et al. DEAD-box RNA helicase DDX23 modulates glioma malignancy via elevating miR-21 biogenesis. Brain. 2015; 138(9): 2553-70.

7. Song JL, Nigam P, Tektas SS, Selva E. MicroRNA regulation of Wnt signaling pathways in development and disease. Cell Signal. 2015; 27(7): 1380-91.

8. Yu Y, Kanwar SS, Patel BB, Oh P-S, Nautiyal J, Sarkar FH, et al. MicroRNA-21 induces stemness by downregulating transforming growth factor beta receptor 2 (TGF-R2) in colon cancer cells. Carcinogenesis. 2012; 33(1): 68-76.

9. Ashraf S, Prichard R. Ivermectin exhibits potent anti-mitotic activity. Vet Parasitol. 2016; 226: 1-4.

10. Crump A. Ivermectin: enigmatic multifaceted 'wonder' drug continues to surprise and exceed expectations. J Antibiot (Tokyo). 2017; 70(5): 495-505.

11. Barlow A, Landolf KM, Barlow B, Yeung SYA, Heavner JJ, Claassen $\mathrm{CW}$, et al. Review of emerging pharmacotherapy for the treatment of coronavirus disease 2019. Pharmacotherapy. 2020; 40(5): 416-37.

12. Tricco AC, Antony J, Zarin W, Strifler L, Ghassemi M, Ivory J, et al. A scoping review of rapid review methods. BMC Med. 2015; 13(1): 224.

13. Mastrangelo E, Pezzullo M, De Burghgraeve T, Kaptein S, Pastorino $\mathrm{B}$, Dallmeier $\mathrm{K}$, et al. Ivermectin is a potent inhibitor of flavivirus replication specifically targeting NS3 helicase activity: new prospects for an old drug. J Antimicrob Chemother. 2012; 67(8): 1884-94.

14. Tay MYF, Fraser JE, Chan WKK, Moreland NJ, Rathore AP, Wang C, et al. Nuclear localization of dengue virus (DENV) 1-4 non-structural protein 5; protection against all 4 DENV serotypes by the inhibitor Ivermectin. Antiviral Res. 2013; 99(3): 301-6.

15. Sharun K, Dhama K, Patel SK, Pathak M, Tiwari R, Singh BR, et al. Ivermectin, a new candidate therapeutic against SARS-CoV-2/ COVID-19. Ann Clin Microbiol Antimicrob. 2020; 19(1): 23.

16. Wagstaff KM, Sivakumaran H, Heaton SM, Harrich D, Jans DA. Ivermectin is a specific inhibitor of importin a/B-mediated nuclear import able to inhibit replication of HIV-1 and dengue virus. Biochem J. 2012; 443(3): 851-6.

17. Lv C, Liu W, Wang B, Dang R, Qiu L, Ren J, et al. Ivermectin inhibits DNA polymerase UL42 of pseudorabies virus entrance into the nucleus and proliferation of the virus in vitro and vivo. Antiviral Res. 2018; 159: 55-62.

18. Raza S, Shahin F, Zhai W, Li H, Alvisi G, Yang K, et al. Ivermectin inhibits Bovine Herpesvirus 1 DNA polymerase nuclear import and interferes with viral replication. Microorganisms. 2020; 8(3): 409.

19. Nguyen KY, Sakuna K, Kinobe R, Owens L. Ivermectin blocks the nuclear location signal of parvoviruses in crayfish, Cherax quadricarinatus. Aquaculture. 2014; 420(421): 288-94.

20. Azeem S, Ashraf M, Rasheed MA, Anjum AA, Hameed R. Evaluation of cytotoxicity and antiviral activity of ivermectin against Newcastle disease virus. Pak J Pharm Sci. 2015; 28(2): 597-602.

21. University Mahidol. A phase II/III, randomized, placebo controlled trial of efficacy and safety of ivermectin in children and adult patients 
with dengue infection [Internet]. National Library of Medicine. 2014. Disponible en: https://clinicaltrials.gov/ct2/show/NCT02045069

22. Kumar R, Gupta N, Kodan P, Mittal A, Soneja M, Wig N. Battling COVID-19: using old weapons for a new enemy. Trop Dis Travel Med Vaccines. 2020; 6(1): 6.

23. Yamasmith E, Avirutnan P, Mairiang D, Tanrumluk S, Suputtamongkol $Y$, Saleh-arong FA, et al. Efficacy and safety of ivermectin against dengue infection: a phase III, randomized, double-blind, placebo-controlled trial [Internet]. En: He 34th Annual Meeting the Royal College of Physicians of Thailand Internal Medicine and One Health, Chonburi, Thailand. 2018. Disponible en: http://www.rcpt.org/abstractdb/ media/abstract/CON2018/Best\%20Resident27/BRA_77_Eakkawit.pdf

24. Yang SNY, Atkinson SC, Wang C, Lee A, Bogoyevitch MA, Borg NA, et al. The broad spectrum antiviral ivermectin targets the host nuclear transport importin a/B1 heterodimer. Antiviral Res. 2020; 177: 104760.

25. Tay MYF, Fraser JE, Chan WKK, Moreland NJ, Rathore AP, Wang C, et al. Nuclear localization of dengue virus (DENV) 1-4 non-structural protein 5; protection against all 4 DENV serotypes by the inhibitor Ivermectin. Antiviral Res. 2013; 99(3): 301-6.

26. Götz V, Magar L, Dornfeld D, Giese S, Pohlmann A, Höper D, et al. Influenza A viruses escape from MXA restriction at the expense of efficient nuclear vRNP import. Sci Rep. 2016; 6(1): 23138.

27. Lundberg L, Pinkham C, Baer A, Amaya M, Narayanan A, Wagstaff $K M$, et al. Nuclear import and export inhibitors alter capsid protein distribution in mammalian cells and reduce Venezuelan Equine Encephalitis Virus replication. Antiviral Res. 2013; 100(3): 662-72.

28. Stońska A, Cymerys J, Skwarska J, Golke A, Bańbura MW. Influence of importin $\alpha / B$ and exportin 1 on equine herpesvirus type 1 (EHV-1) replication in primary murine neurons. Pol J Vet Sci. 2013; 16(4): 749-51.

29. Bennett SM, Zhao L, Bosard C, Imperiale MJ. Role of a nuclear localization signal on the minor capsid Proteins VP2 and VP3 in BKPyV nuclear entry. Virology. 2015; 474: 110-6.

30. Atkinson SC, Audsley MD, Lieu KG, Marsh GA, Thomas DR, Heaton SM, et al. Recognition by host nuclear transport proteins drives disorderto-order transition in Hendra virus V. Sci Rep. 2018; 8(1): 358.

31. Wang X, Lv C, Ji X, Wang B, Qiu L, Yang Z. Ivermectin treatment inhibits the replication of Porcine circovirus 2 (PCV2) in vitro and mitigates the impact of viral infection in piglets. Virus Res. 2019; 263: 80-6.

32. Varghese FS, Kaukinen P, Gläsker S, Bespalov M, Hanski L, Wennerberg $\mathrm{K}$, et al. Discovery of berberine, abamectin and ivermectin as antivirals against chikungunya and other alphaviruses. Antiviral Res. 2016; 126: 117-24.

33. Rizzo E. Ivermectin, antiviral properties and COVID-19: a possible new mechanism of action. Naunyn Schmiedebergs Arch Pharmacol. 2020; 393(7): 1153-6.

34. Nguyen C, Burton T, Kuklinski W, Gray M, Foy B. Ivermectin for the Control of West Nile Virus Transmission. Eur J Mol Clin Med. 2015; 2(4-5): 127.

35. Lee YJ, Lee C. Ivermectin inhibits porcine reproductive and respiratory syndrome virus in cultured porcine alveolar macrophages. Arch Virol. 2016; 161(2): 257-68.

36. Wurm $\mathrm{T}$, Chen $\mathrm{H}$, Hodgson T, Britton P, Brooks G, Hiscox JA. Localization to the Nucleolus Is a Common Feature of Coronavirus Nucleoproteins, and the Protein May Disrupt Host Cell Division. J Virol. 2001; 75(19): 9345-56.

37. Wulan WN, Heydet D, Walker EJ, Gahan ME, Ghildyal R. Nucleocytoplasmic transport of nucleocapsid proteins of enveloped RNA viruses. Front Microbiol. 2015; 6.

38. Surjit M, Lal SK. The nucleocapsid protein of the SARS Coronavirus: structure, function and therapeutic potential. En: Molecular Biology of the SARS-Coronavirus [Internet]. Berlin, Heidelberg: Springer Berlin Heidelberg; 2010. p. 129-51.

39. Timani KA, Liao Q, Ye L, Zeng Y, Liu J, Zheng Y, et al. Nuclear/ nucleolar localization properties of $\mathrm{C}$-terminal nucleocapsid protein of SARS coronavirus. Virus Res. 2005; 114(1-2): 23-34.

40. Rowland RRR, Chauhan V, Fang Y, Pekosz A, Kerrigan M, Burton MD. Intracellular localization of the Severe Acute Respiratory Syndrome coronavirus nucleocapsid protein: absence of nucleolar accumulation during infection and after expression as a recombinant protein in vero cells. J Virol. 2005; 79(17): 11507-12.

41. Caly L, Druce JD, Catton MG, Jans DA, Wagstaff KM. The FDAapproved drug ivermectin inhibits the replication of SARS-CoV-2 in vitro. Antiviral Res. 2020; 178: 104787.

42. Sandler ZJ, Vu MN, Menachery VD, Mounce BC. Novel ionophores active against La Crosse virus identified through rapid antiviral screening. bioRxiv. 2020.

43. Klotz U, Ogbuokiri JE, Okonkwo PO. Ivermectin binds avidly to plasma proteins. Eur J Clin Pharmacol. 1990; 39(6): 607-8.

44. Velthuis AJW, Van den Worm SHE, Sims AC, Baric RS, Snijder EJ, Van Hemert MJ. Zn2+ inhibits coronavirus and arterivirus RNA polymerase activity in vitro and zinc ionophores block the replication of these viruses in cell culture. PLoS Pathog. 2010; 6(11): e1001176.

45. Khailany RA, Safdar M, Ozaslan M. Genomic characterization of a novel SARS-CoV-2. Gene Reports. 2020; 19: 100682.

46. Adedeji AO, Sarafianos SG. Antiviral drugs specific for coronaviruses in preclinical development. Curr Opin Virol. 2014; 8: 45-53.

47. Mirza MU, Froeyen M. Structural elucidation of SARS-CoV-2 vital proteins: computational methods reveal potential drug candidates against main protease, Nsp12 polymerase and Nsp13 helicase. J Pharm Anal. 2020.

48. Khater S, Das G. Repurposing ivermectin to inhibit the activity of SARS CoV2 helicase: possible implications for COVID 19 therapeutics. OSF Prepr. 2020.

49. Changeux J-P, Amoura Z, Rey FA, Miyara M. A nicotinic hypothesis for Covid-19 with preventive and therapeutic implications. Comptes Rendus Biol. 2020; 343(1): 33-9.

50. Russo P, Bonassi S, Giacconi R, Malavolta M, Tomino C, Maggi F. COVID-19 and Smoking. Is Nicotine the Hidden Link?. Eur Respir J. 2020.

51. Ulloa L. The vagus nerve and the nicotinic anti-inflammatory pathway. Nat Rev Drug Discov. 2005; 4(8): 673-84.

52. Farsalinos K, Niaura R, Le Houezec J, Barbouni A, Tsatsakis A, Kouretas D, et al. Editorial: Nicotine and SARS-CoV-2: COVID-19 may be a disease of the nicotinic cholinergic system. Toxicol Reports. 2020; 7: 658-63.

53. García-Hernández M, Guerrero-Ramírez G, Castro-Corona MA, Medina-de-la-Garza CE. Inmunomoduladores como terapia adyuvante en la enfermedad infecciosa. Med Univ. 2009; 11(45): 247-59.

54. Blakley BR, Rousseaux CG. Effect of ivermectin on the immune response in mice. Am J Vet Res. 1991; 52(4): 593-5.

55. Zheng HJ, Piessens WF, Tao ZH, Cheng WF, Wang SH, Cheng SH, et al. Efficacy of ivermectin for control of microfilaremia recurring after treatment with diethylcarbamazine. I. Clinical and parasitologic observations. Am J Trop Med Hyg. 1991; 45(2): 168-74.

56. Alvinerie M, Escudero E, Sutra JF, Eeckhoutte C, Galtier P. The pharmacokinetics of moxidectin after oral and subcutaneous administration to sheep. Vet Res. 1998; 29(2): 113-8.

57. González Canga A, Sahagún Prieto AM, Diez Liébana MJ, Fernández Martínez N, Sierra Vega M, García Vieitez JJ. The pharmacokinetics and interactions of ivermectin in humans: a mini-review. AAPS J. 2008; 10(1): 42-6.

58. Okonkwo PO, Ogbuokiri JE, Ofoegbu E, Klotz U. Protein binding and ivermectin estimations in patients with onchocerciasis. Clin 
Pharmacol Ther. 1993; 53(4): 426-30.

59. Whitworth JAG, Hay CRM, McNicholas AM, Morgan D, Maude GH, Taylor DW. Coagulation abnormalities and ivermectin. Ann Trop Med Parasitol. 1992; 86(3): 301-5.

60. Heidary F, Gharebaghi R. Ivermectin: a systematic review from antiviral effects to COVID-19 complementary regimen. J Antibiot (Tokyo). 2020.

61. Croci R, Bottaro E, Chan KWK, Watanabe S, Pezzullo M, Mastrangelo $E$, et al. liposomal systems as nanocarriers for the antiviral agent ivermectin. Int J Biomater. 2016; 2016: 1-15.

62. Rueda A. Fármacos para COVID-19 sin respaldo calan hondo en Latinoamérica [Internet]. SciDev.Net. 2020. Disponible en: https://bit.ly/2zydu1K

63. Parisi K. Perú da impulso a hidroxicloroquina e ivermectina como tratamiento para COVID-19. Cable News Network CNN. 2020.

64. Podcast RPP. Coronavirus en Perú: Experiencia médica funcionó en pacientes peruanos [Audiogalería] [Internet]. RPP. 2020. Disponible en: https://bit.ly/3dUwSUO

65. Gestión R. Hospital de San Juan de Lurigancho elabora Ivermectina para tratamiento a pacientes COVID-19 [Internet]. Gestión Perú. 2020. Disponible en: https://bit.ly/2BjWOMA

66. Solomon S. FDA Letter to Stakeholders: do not use ivermectin intended for animals as treatment for COVID-19 in Humans. FDA's Center for Veterinary Medicine. 2020.

67. Juarez M, Schcolnik-Cabrera A, Dueñas-Gonzalez A. The multitargeted drug ivermectin: from an antiparasitic agent to a repositioned cancer drug. Am J Cancer Res. 2018; 8(2): 317-31.

68. Jang Y, Shin JS, Yoon Y-S, Go YY, Lee HW, Kwon OS, et al. Salinomycin inhibits Influenza Virus infection by disrupting endosomal acidification and viral matrix protein 2 function. J Virol. 2018; 92(24).

69. Frick D, Lam A. understanding helicases as a means of virus control. Curr Pharm Des. 2006; 12(11): 1315-38.

70. Ulrich H, Pillat MM. CD147 as a Target for COVID-19 treatment: suggested effects of azithromycin and stem cell engagement. Stem Cell Rev Reports. 2020; 16(3): 434-40.

71. ClinicalTrials.gov. Ivermectin and COVID-19 [Internet]. National Library of Medicine. 2020. Disponible en: https://clinicaltrials.gov/ ct2/results?term=ivermectin\&tcond=Covid-19

72. Simșek Yavuz S, Ünal S. Antiviral treatment of COVID-19. Turkish J Med Sci. 2020; 50(Suppl. 1): 611-9.

\section{Correspondencia:}

Jorge Arturo Vega-Fernández

Dirección: Av. Paul Harris Nº53. La Victoria. Chiclayo, Lambayeque.

Teléfono: 972968376

Correo electrónico: jarturo.vegaf@gmail.com

\section{Recibido: 01 de julio de 2020}

Evaluado: 16 de octubre de 2020

Aprobado: 04 de noviembre de 2020

( $)$ La revista. Publicado por Universidad de San Martín de Porres, Perú. (cc) Br Licencia de Creative Commons Artículo en acceso abierto bajo términos de Licencia Creative Commons Atribución 4.0 Internacional. (http://creativecommons.org/licenses/by/4.0/)

\section{ORCID iDs}

Jorge Arturo Vega-Fernández Thttps://orcid.org/0000-0003-0073-033X

Danny Omar Suclupe-Campos io https:// orcid.org/0000-0003-4930-3689

Franklin Rómulo Aguilar-Gamboa ㄴ https://orcid.org/0000-0003-1943-5613 